\title{
Collaborative National Program for the Development and Performance Testing of Distributed Power Technologies with Emphasis on Combined Heat and Power Applications
}

\author{
Final Scientific/Technical Report
}

Prepared for

U.S. Department of Energy

Cooperative Agreement: Instrument No. DE-FC36-02G012017

\author{
Prepared by \\ Association of State Energy Research and Technology Transfer Institutions \\ (ASERTTI) \\ 455 Science Dr. \#200 \\ Madison, WI 53711
}

Project Director: Arthur Soinski PhD, California Energy Commission Associate Project Director: Mark Hanson PhD, ASERTTI

The following are the Program Sponsors (S) and Steering Committee (SC) members:

California Energy Commission (S:SC): Arthur Soinski and Terry Thompson

Concurrent Technology Corporation (SC): Terry Conrad

Energy Center of Wisconsin (SC): Sherry Benzmiller, Joe Kramer, and Susan Stratton

Illinois Department of Commerce and Economic Opportunity (S):

Montana State University-Billings (SC): Brian Gurney

National Renewable Energy Laboratory (SC): Lynnae Boyd and Paul Bergeron

New York State Energy Research and Development Authority (S:SC): Richard Drake and Jim Foster

University of Illinois-Chicago, Energy Resources Center (SC): Steffen Mueller

U.S. Department of Defense Fuel Cell Test and Evaluation Center (S)

U.S. Department of Energy (S:SC): Debbie Haught

U.S. Environmental Protection Agency (S)

June 28, 2006 


\section{Table of Contents}

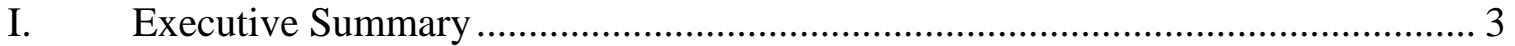

II. Comparison of Goals and Objectives to Actual Accomplishments....................... 5

III. Summary of Project Activities....................................................................... 7

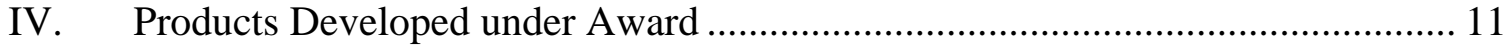

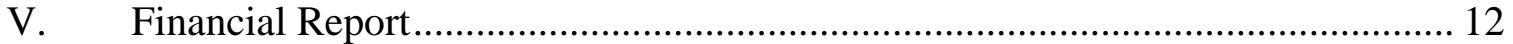




\section{EXECUTIVE SUMMARY}

Distributed generation (DG) technologies are emerging as a viable supplement to centralized power production. DG technologies are being used with combined heat and power (CHP) systems to increase overall systems efficiency and improve economic performance. Independent evaluations of DG and DG/CHP technologies are required to assess performance of systems, and, ultimately, assess the applicability and efficacy of a specific technology at any given site. A current barrier to public acceptance of DG and DG/CHP technologies is the lack of credible and uniform information regarding system performance. Therefore, as new DG and DG/CHP technologies are developed and introduced to the marketplace, uniform and repeatable methods of evaluating the performance of these systems that are nationally accepted are needed.

Under this Cooperative Agreement, four performance testing protocols and a searchable database have been developed and are operational. The protocols serve as a uniform basis in the U.S. and possibly beyond for evaluating the performance of DG and DG/CHP systems and enabling comparisons and evaluations based on applications, locations, local utility rates, and requirements. The national protocols are for laboratory testing, field (intensive onsite short-term) testing, long-term monitoring, and case studies. The searchable database and protocols are intended for DG and DG/CHP systems up to 3 MW in laboratory testing and up to $7 \mathrm{MW}$ in field testing and monitoring.

The protocols are intended for public use by organizations such as manufacturers, universities, laboratories, and other capable testing agencies to assess the performance attributes of commercial DG and DG/CHP products up to three (3) megawatts in capacity. Results of testing are ultimately intended for end users, manufacturers, utilities, system integrators, engineers, and regulators. The protocols cover laboratory quality performance testing of gas-turbine, reciprocating engines including internal combustion (IC) and Stirling Cycle, and microturbine-based products. Fuel Cell Power Systems (FCPS) are beyond the scope of this cooperative agreement and will be addressed in Phase 2.

In addition to the tests themselves, the protocols describe consistent methods for preparing tests, analyzing data, and calculating and reporting test results. They include grid-connected, stand-alone, and transient operating performance. The protocols do not describe setting up the CHP system or its commissioning and decommissioning.

The protocols include the following performance test elements for DG and CHP systems:

- $\quad$ Power output and efficiency

- $\quad$ Standby and transient performance

- Emissions

- $\quad$ Noise

The National Searchable Database only includes data collected using an interim DG and DG/CHP National Performance Protocols. The protocols are interim because the final protocols will be based on early application feedback and input from the Stakeholder Advisory Committee (SAC) and public users. This application process takes time as DG and DG/CHP systems are procured, installed, and operated in the marketplace or in other 
cases tested in laboratory settings. The project Steering Committee (SC) is continuing the work described in a Phase 2 effort and is gathering user information and feedback to guide protocol adjustments as needed and subsequently issue final protocols in 2007.

These protocols are available at www.dgdata.org managed by ASERTTI for use by all interested parties, including distributed generation and combined heat and power system users, manufacturers, developers, utilities, engineers, and R\&D organizations. A second publicly available database linked to the ASERTTI site is the New York DG/CHP Integrated Data System available at http://chp.nyserda.org. This database uses the national protocols and provides public access to additional long-term monitoring data on DG/CHP sites. The New York site has a second location where detailed, real-time operational data for a limited number of sites can be observed.

The searchable databases enable interested parties to make inquiries and find performance results based upon a variety of parameters. Inquiries can include results from laboratory testing, field testing, long-term monitoring for a limited set of parameters, and case studies. Only data collected according to the protocols will be included in the databases; therefore users can have confidence that the data are comparable. In cases where reported data on the New York Integrated Data System (a linked data source separate from the dgdata.org site) do not fully meet protocol requirements, the data is noted as non-compliant. 


\section{COMPARISON OF GOALS AND OBJECTIVES TO ACTUAL ACCOMPLISHMENTS}

The project team has successfully completed all task elements in the Cooperative Agreement's Statement of Work. These task and sub-task elements are listed in Table 1 and their status indicated.

The protocols, the database, the report on the Controlled Laboratory Testing using the Laboratory Protocol, and the reports on the Field Testing using the Field Testing Protocol are or will be publicly provided at the ASERTTI project website: www.dgdata.org. The same site also provides the two case studies for Midwest sites per the Case Study protocol.

The SAC that was established is described in the next section of this report. The SAC was convened for meetings in Chicago and Los Angeles to provide critique of the work under Task 1 and Task 2.

Table 1. Scope of Work - Cooperative Agreement

\begin{tabular}{|c|c|c|c|}
\hline Task & Sub-Task & Description & Disposition \\
\hline \multirow[t]{5}{*}{1} & & $\begin{array}{l}\text { Protocol, Database, and Related Quality } \\
\text { Control Development }\end{array}$ & \\
\hline & 1.1 & Development of Laboratory and Field-Test Protocols & Completed \\
\hline & 1.2 & $\begin{array}{l}\text { Database and Quality Control Development and } \\
\text { Integration of Connectivity Protocols }\end{array}$ & Completed \\
\hline & 1.3 & $\begin{array}{l}\text { Establish Case Study Protocol and Prepare at least one } \\
\text { Case Study }\end{array}$ & Completed \\
\hline & 1.4 & $\begin{array}{l}\text { Engage SAC and other Stakeholders in Critique of Task } 1 \\
\text { Products }\end{array}$ & Completed \\
\hline \multirow[t]{6}{*}{2} & & $\begin{array}{l}\text { Laboratory and Field Protocol Testing and } \\
\text { Initial Refinement }\end{array}$ & \\
\hline & 2.1 & $\begin{array}{l}\text { Initial Test and Refinement of Laboratory and Field } \\
\text { Testing Protocols in Selected DG/CHP Projects in } \\
\text { California }\end{array}$ & Completed \\
\hline & 2.2 & $\begin{array}{l}\text { Initial Test and Refinement of Laboratory and Field } \\
\text { Testing Protocols in Selected DG/CHP Projects in New } \\
\text { York }\end{array}$ & Completed \\
\hline & 2.3 & $\begin{array}{l}\text { Initial Implementation of Case Study Protocols in } \\
\text { selected DG/CHP Projects in Midwest region }\end{array}$ & Completed \\
\hline & 2.4 & $\begin{array}{l}\text { Initial Implementation of Database and Quality Control } \\
\text { Specifications }\end{array}$ & Completed \\
\hline & 2.5 & $\begin{array}{l}\text { Engage SAC and other Stakeholders in Critique of Task } 2 \\
\text { products }\end{array}$ & Completed \\
\hline \multirow[t]{4}{*}{3} & & $\begin{array}{l}\text { Formal Protocol Implementation, Data } \\
\text { Collection and Reporting }\end{array}$ & \\
\hline & 3.1 & $\begin{array}{l}\text { Controlled Laboratory Testing of DG/CHP Systems } \\
\text { using Protocols }\end{array}$ & Completed \\
\hline & 3.2 & Field Testing of DG/CHP Systems using Protocols & Completed \\
\hline & 3.3 & Database Management & Completed \\
\hline
\end{tabular}




\begin{tabular}{|c|c|l|c|}
\hline Task & Sub-Task & \multicolumn{1}{|c|}{ Description } & Disposition \\
\hline & 3.4 & $\begin{array}{l}\text { Technology Transfer, Assessment of Project Impact and } \\
\text { Final Report }\end{array}$ & Completed \\
\hline $\mathbf{4}$ & & ASERTTI Project Management & Completed \\
\hline & 4.1 & Project Management and Coordination & Completed \\
\hline & 4.2 & Contracting, Funding and Subcontract Management & Completed \\
\hline & 4.3 & Establish SAC to Guide Project & Completed \\
\hline
\end{tabular}




\section{SUMMARY OF PROJECT ACTIVITIES}

Project activities were conducted pursuant to the terms of the Collaborative National Program for the Development and Performance Testing of Distributed Power Technologies with Emphasis on Combined Heat and Power Applications, co-sponsored by the U.S. Department of Energy and members of the Association of State Energy Research and Technology Transfer Institutions (ASERTTI). ASERTTI sponsoring members were the California Energy Commission, Concurrent Technologies Corporation, Energy Center of Wisconsin, Montana State University-Billings, New York State Energy Research and Development Authority, and University of Illinois-Chicago. Other sponsors were the Illinois Department of Commerce and Economic Opportunity, U.S. Department of Defense Fuel Cell Test and Evaluation Center, and U.S. Environmental Protection Agency Office of Research and Development. The program was managed by ASERTTI.

The protocol development program was directed by several guiding principles specified by the ASERTTI Steering Committee:

- Development of protocols using a stakeholder driven process.

- Use of existing standards and protocols wherever possible.

- Development of cost-effective, user-friendly protocols that provide credible, quality data without excessive implementation costs.

- Validation of protocols prior to final publishing by using them and revising them, based on the validation test results. The interim protocols will become final protocols after use and validation of these interim protocols.

The laboratory protocol was developed based on input and guidance provided by two stakeholder groups, the ASERTTI Stakeholder Advisory Committee and the UL Stakeholder Technical Panel, managed by UL. The SAC consisted of 26 stakeholders representing manufacturers, end-users, research agencies, regulators, and demonstrators. The UL Stakeholder Technical Panel consists of 37 members, listed in this document.

The ASERTTI Steering Committee directed the project and provided review and final approval of the original interim protocol. GTI developed the protocol with assistance from the UL Stakeholder Technical Panel.

The protocol development process consisted of several steps following ASERTTI's guiding principles. First, a list of performance parameters for which laboratory and field testing protocols should be written was completed. The parameters selected provide performance data for electrical generation, electrical efficiency, thermal efficiency, atmospheric emissions, acoustic emissions, and operational performance.

The laboratory, field, long-term monitoring and case study protocols' development was based on existing standards, protocols, and the experience of the committees. Existing standards and protocols potentially applicable to DG systems were reviewed and evaluated. The existing standards and protocols formed the basis for instrument specifications, acceptable test methods, QA/QC procedures, calculations, and other requirements of this protocol. The laboratory protocol allows for the controlled 
evaluation of the effects of several parameters on performance of the unit that cannot be reasonably verified in field testing. Laboratory testing also allows testers to determine performance under conditions that cannot be practically controlled in a field setting, such as ambient conditions, response to upsets, and grid-isolated (stand-alone) operation for determining transient response characteristics.

Reasonable compromises were sought to provide a balance between the requirement for credible, high-quality data, and requirements that these protocols be user-friendly and enable low-cost testing, so that they can be widely and consistently implemented and reported on the Searchable Database at NREL.

Figure 1 shows the program management structure and individuals that were involved in the laboratory protocol development. Gas Technology Institute (GTI) was the subcontractor for this work.

\section{Figure 1. Laboratory Test Protocol Development Contributors}

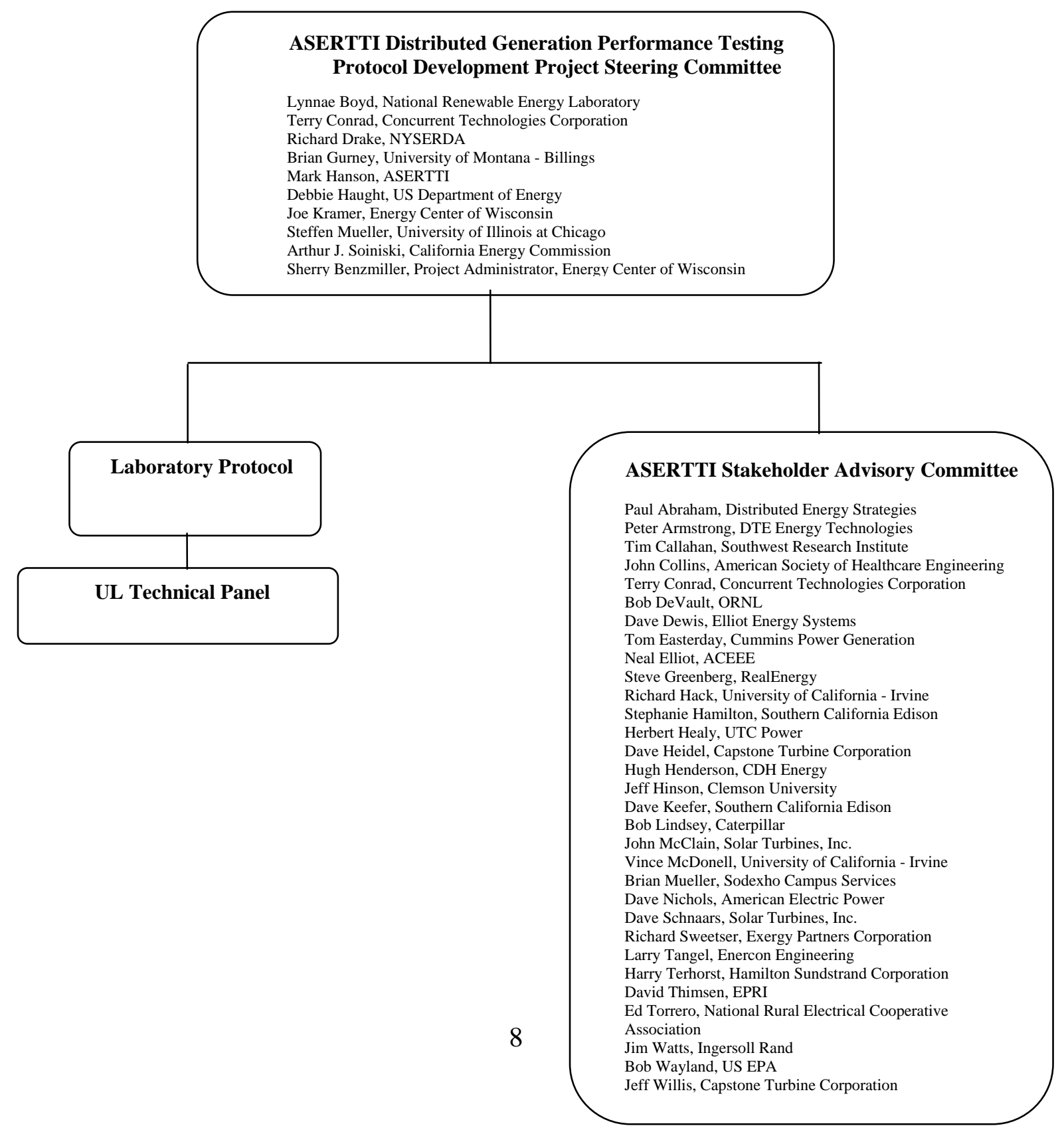


Figure 2 shows the management structure for the Field Testing Protocol. The Southern Research Institute (SRI) was the subcontractor for this work.

\section{Figure 2. Field Test Protocol Development Contributors}

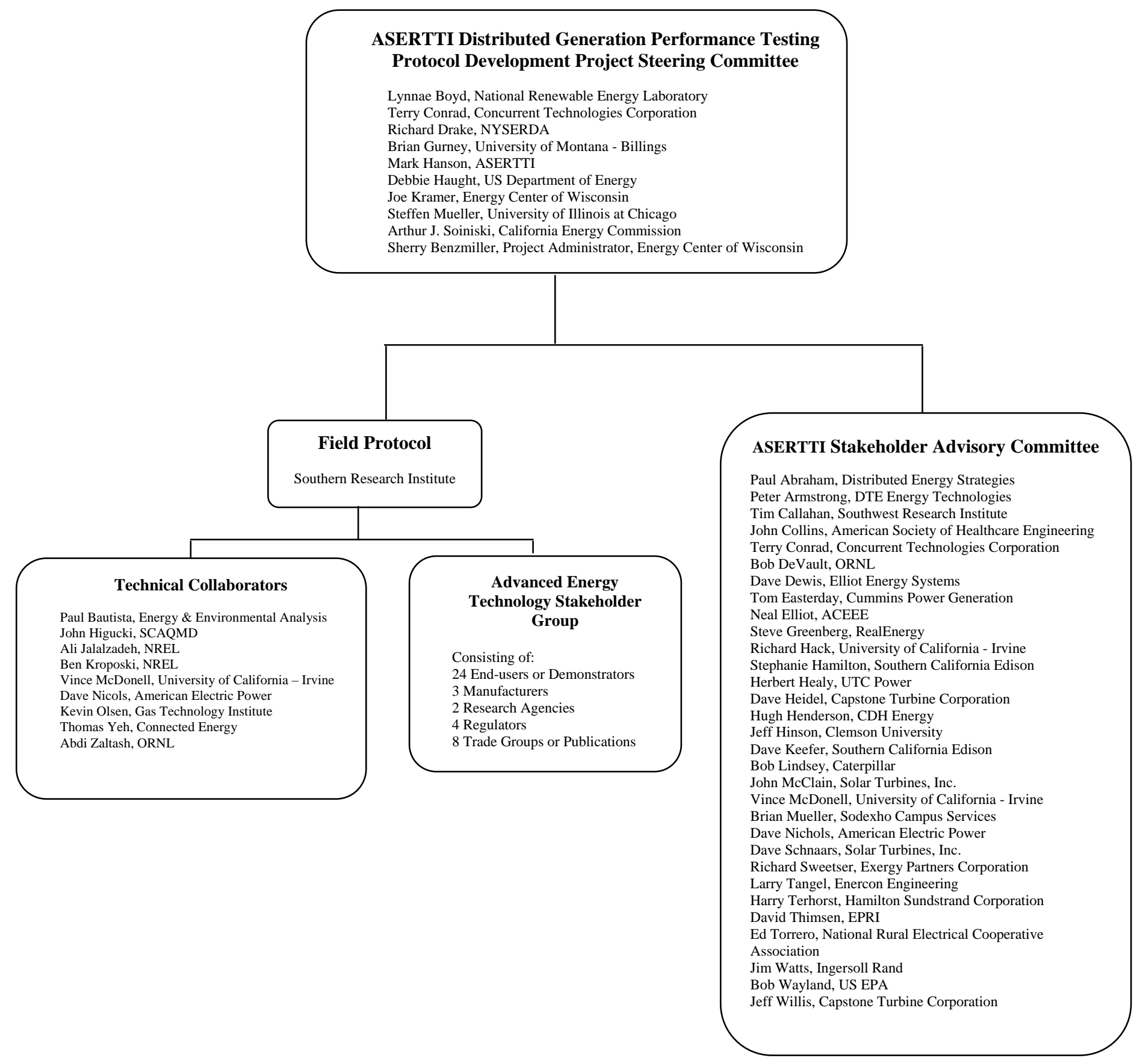


Connected Energy Corporation was the subcontractor for the Long-Term Monitoring Protocol. The University of Illinois-Chicago Energy Resources Center developed the Case Study Protocol.

The interim protocols are a full protocol. The term "interim" was used to indicate that the program was gathering experience and feedback from users applying the protocols, and that information would be used to make appropriate adjustments at a future date in what would be termed a final protocol. The program participants are continuing their collaborative work beyond the Statement of Work in the current program. A Phase 2 effort includes new tasks, funding, and additional participants are being added. Final Protocols will be issued in 2007 when sufficient experience and feedback has been provided from the Interim Protocols. Feedback and results of the validation process will be reviewed by the SAC. The Phase 2 Steering Committee including the Department of Energy member will complete the review and issue the final protocols.

The performance results of DG and DG/CHP systems tested and/or monitored with the protocols are housed in a free searchable database managed by the National Renewable Energy Laboratory (NREL) and located at www.dgdata.org. This site was developed by NREL and reviewed by the SAC and SC. This database was made available to the public on October 27, 2005. The database is now being populated as data per the protocols become available. For the public to truly benefit from this effort, it is crucial that the database be supported on an ongoing basis. This will be done for the next three years under Phase 2 of this program. It is anticipated that database population will accelerate over time.

Although not required in the Statement of Work, the SC members recognized the value of posting additional data for New York applications being gathered under the protocols. The New York DG/CHP Integrated Data System is available at www.dgdata.org or at http://chp.nyserda.org.

Although it is beyond the scope of the current program, we note that the Phase 2 program is including Stirling Cycle as part of the reciprocating engine generator technology, and is adding fuel cell power systems (FCPS). FCPS are electrochemical systems that convert the chemical energy of a reaction directly into electrical energy, water, and heat. The electrochemical reaction may use phosphoric acid (PAFC), polymer electrolyte membrane (PEMFC), solid oxide (SOFC), molten carbonate (MCFC), or Alkaline (AFC). 


\section{PRODUCTS DEVELOPED UNDER AWARD}

A website www.dgdata.org provides the following products:

- Laboratory Protocol

- Field Testing Protocol

- Long-Term Monitoring Protocol

- Case Study Protocol

- National Searchable Database

The New York DG/CHP Integrated Data System is available through www.dgdata.org or through http://chp.nyserda.org 


\section{FINANCIAL REPORT}

\begin{tabular}{|lr|}
\hline Fund Allocation & DOE Funding Amount \\
NYSERDA & $\$ 300,000.00$ \\
University of Illinois at Chicago & $\$ 90,000.00$ \\
Energy Center of Wisconsin & $\$ 95,000.00$ \\
Gas Technology Institute & $\$ 200,000.00$ \\
Southern Research Institute & $\$ 314,927.00$ \\
\hline ASERTTI TOTAL & $\$ 999,927.00$ \\
\hline
\end{tabular}

\begin{tabular}{|lr|}
\hline Co-funding Source & Co-funding Amount \\
California Energy Commission & $\$ 7,547,110.00$ \\
NYSERDA & $\$ 532,530.74$ \\
Illinois Department of Commerce and Community Affairs & $\$ 59,469.00$ \\
\hline TOTAL & $\mathbf{\$ 8 , 1 3 9 , 1 0 9 . 7 4}$ \\
\hline
\end{tabular}

These funds do not include in-kind funding and support from the U.S. Environmental Protection Agency and Steering Committee member organizations. 


\section{UL STAKEHOLDER TECHNICAL PANEL}

Member

John Collins

Dave Nichols

Tony Hynes

Grant Chin

Cu Huynh

Bryan Fox

Jeff Willis

Robert Lindsey

Ben Matthews

Jim McWalters

John Schwab

Joel Puncochar

Brent Boyd

Gus Kuklinski

Herb Whittall

Dave Dewis

Greg Dettmer

Doug Hay

Jeff Jonas

Jim Watts

Patrick Reinks

David Kammer

Bill Mueller

Mike Duhamel

Gary Papas

Steve Chippas

Bob DeVault

Leslie Witherspoon

John McClain

Stephanie Hamilton

Robert Yinger

Rod Schwedler

Vince McDonnell

John Cuttica

Gary Nowakowski

John Hoeft

Hans Melberg
Company

American Society for Healthcare Engineering

American Electric Power

Bowman Power Group

California Environmental Protection Agency

Calnetix, Inc.

Capstone Microturbine Corporation

Capstone Microturbine Corporation

Caterpillar Inc.

Caterpillar Inc.

City of Milwaukee

City of Wauwatosa

Cummins Power Generation

DeVilbiss

DTE Energy Technologies, Inc.

Electrical Generating Systems Association

Elliott Energy Systems, Inc.

Elliott Energy Systems, Inc.

FG Wilson Ltd.

Generac Power Systems, Inc.

Ingersoll Rand Company Limited

Ingersoll Rand Company Limited

Katolight Corporation

Kohler Engines

Marathon Electric

Marathon Electric

MWH Global, Inc.

Oak Ridge National Laboratory

Solar Turbines Incorporated

Solar Turbines Incorporated

Southern California Edison

Southern California Edison

Southern California Gas Company

University of California, Irvine

University of Illinois - Chicago

U.S. Department of Energy

Waukesha Engine Division

Waukesha Engine Division 